\title{
Perception of Nurses Regarding Organizational Justice and Ethical Behavior; Organızational Culture in Hospitals
}

\author{
Zeynep Özsoy ${ }^{1}$, Dilek Ekici ${ }^{2 *}$ \\ ${ }^{1}$ Gazi Mustafa Kemal Governmental Hospital, Ankara, Turkey \\ ${ }^{2}$ Nursing Department, Faculty of Health Sciences, Gazi University, Ankara, Turkey
}

*Corresponding Author: Dilek Ekici, Associate Professor, PhD, RN, Nursing Department, Faculty of Health Sciences, Gazi University, Besevler, Ankara, Turkey. Email: docdrdilekekici@gmail.com

Received March 27, 2017; Accepted April 24, 2017; Online Published May 24, 2017

\begin{abstract}
Background: The organizational culture, justice, and ethical practices found in nursing services and health services have numerical superiority and a significant importance.

Objective: This descriptive study aimed to determine the relationship among ethical behavior, organizational justice and culture in public and private hospitals.

Methods: One hundred fifty-three nurses working for at least 6 months in a private or public hospital in Ankara participated in this study. The questionnaire used in this study consisted of three parts: participant demographic data, the ethical leadership scale, and organizational justice.

Results: The perceptions regarding organizational culture and ethical behavior of nurses working in a private hospital were found to be greater than those of nurses working in a public hospital. A statistically significant relationship was found between the nurses' perceptions of organizational culture and justice. A similar relationship between perceptions of nurses regarding organizational culture and ethical behavior was also noted. The results showed that organizational culture explained $30 \%$ of the ethical leadership behavior of managers and 35\% of organizational justice.

Conclusion: The perceptions of nurses regarding justice and ethical behaviors are significantly affected by their work culture exposed in the case of increasing of non-ethic and non-fair behaviours it was the nurses perceive more strength and role culture.
\end{abstract}

Keywords: Organizational culture, Justice, Ethics, Behavior, Nurses

\section{Background}

Organizational culture is a notion that was introduced in the 1980s and later gained more and more significance as the role of organizational loyalty in the success of organizations in South Korea and Japan, and it became a frequently discussed topic. Organizational culture is the combination of values, beliefs, and behaviors which are unique to an organization and contribute to its overall environment. ${ }^{1}$

The development of an organizational culture is an extremely complex process. Researchers investigating organizational culture usually address it on the basis of managers and management. However, it is a process in which innumerable factors are involved. ${ }^{2}$

Founding individual(s) are the dominant actors in creating and developing the organizational culture of an entity. In other words, the fundamental values, beliefs, and norms of the founding member(s) of an organization, i.e. entrepreneurs who undertake a business venture and design the framework of its organizational culture, constitute the basis for organizational development and an organization's unique culture. ${ }^{3}$

A dynamic organizational culture embraced by all employees, thanks to common values, provides an institution with coalescence and a harmonious working environment, which facilitates the achievement of any goal. Employees in organizations tend to compare themselves with other personnel, questioning, not only in terms of results, but also in respect of processes, the working conditions such as equal pay for equal performance, existence of rules equally applied to all members of the organization, and the fair distribution of tasks. Given the nature of the matter, nurses working at a management level should assume great responsibilities. In trying to respond to such questioning, they should act in accordance with laws and legislations and adopt a correct and equitable

Copyright (C) 2017 The Hospital Practices and Research. This is an open-access article distributed under the terms of the Creative Commons Attribution License (http://creativecommons.org/licenses/by/4.0), which permits unrestricted use, distribution, and reproduction in any medium, provided the original work is properly cited. 
conduct marked by fairness, frankness and a sense of responsibility toward their subordinates.

Different notions have arisen in line with advances in the healthcare sector, one of which is justice perceived by employees within the organization in which they work. Organizational justice is defined as a fundamental principle of the common activities and actions based on teamwork in organizations. The notion of justice is widely researched, and many scientific studies on organizational structure address it as a social notion. Greenberg suggested that a conduct which is considered to be equitable by the majority is defined as fair. ${ }^{4}$

Justice has a great significance in organizations characterized by fierce competition. While the perception of an organization as fair by employees has a positive effect on organizational loyalty and job satisfaction, the opposite situation can lead to job burnout, low performance, and dissatisfaction. ${ }^{5}$

Ethics is a philosophical discipline that investigates the values, norms, and rules making up the basis of human relations, be it at an individual or social level, in terms of morality by defining them as wrong-right or good-bad. The word ethics derives from the Greek word "ethos" which means character. Ethical problems can force individuals to make difficult choices under uncertain and complex conditions. It is difficult to decide whether or not a decision is the best, because every option can have better aspects than another one. An impartial decision made on the basis of causes and judged, at the same time, as fair by others evidences that one's perspective is right. Those who take special care to have moral justification in their decisionmaking processes do make fair and good decisions. ${ }^{6,7}$

\section{Objective}

In the nursing profession, ethics in management differs not only from clinical ethics, but also from other fields in terms of the managerial approach. Even though the roles of managing and non-managing nurses share certain responsibilities and similarities, many management functions are unique to the profession of nursing, particularly those involving ethical contradictions. ${ }^{8}$ Organizational culture reflects the management and leadership style that is dominant in the institution. Accordingly, it is predicted that, as the leadership behavior of managers becomes more unethical, the perception of organizational justice and culture by employees is affected.

This descriptive study aimed to provide insights into the effects of organizational culture in hospitals on the behavior patterns of nurses in respect to ethical and fair conduct. To this end, the study sought to address the following research questions:

- What are the demographic characteristics of the nurses participating in the study?

- Upon what structures do hospitals base their organizational culture?

- Is there any difference between ethical conduct and organizational structures?

- Do the structures of organizational culture have an effect on organizational justice and ethical conduct?

\section{Methods}

\subsection{Type of Study}

The study was based on the descriptive correlative research model.

\subsection{Study Sample}

Stratified sampling was performed, and one private hospital and one public hospital were chosen for this study. Written requests to perform the research which explained the study's purpose and method were sent to the selected hospitals. The data collection process began after permission to conduct the study was obtained. The study population consisted of 107 nurses serving in a public hospital located in the province of Ankara in which the healthcare quality standards set by the Ministry of Healthcare are applied and 96 nurses employed in a private hospital accredited by the Joint Commission International. A total of 153 nurses who had been serving in their respective hospitals for 6 months participated in the study.

\subsection{Data Collection Tools}

Data was collected by means of the "Socio-demographic Questionnaire," "Organizational Culture Scale," "Organizational Justice Perception Scale," and the "Ethical Behaviors Scale." The Socio-demographic Questionnaire included 8 questions.

\subsubsection{Organizational Culture Scale}

This study employed the Organizational Culture Scale developed and validated by İpek. ${ }^{9}$ It included 37 items and 4 sub-dimensions (power, role, success, and support).

\subsubsection{Organizational Justice}

To determine nurses' perceptions of organizational justice, the "Organizational Justice Scale (OJS)" developed by Colquitt ${ }^{10}$ was used. Adaptation of the scale to Turkish was validated by Özmen et al. ${ }^{11}$

\subsubsection{Ethical Behaviors Scale}

The Ethical Behaviors Scale developed and validated by Kara comprised 36 items and 4 sub-dimensions (tolerance, justice, responsibility, honesty). ${ }^{6}$ This scale was also prepared on the basis of the Likert scale consisting of 5 levels typical to it: strongly favorable (5), somewhat favorable (4), undecided (3), somewhat unfavorable (2) and strongly unfavorable (1).

\subsection{Data Collection}

The researcher initially informed the nurses about the scope of the study. Then, the participating nurses signed a consent form and responded to the questions on the data collection forms. The Socio-demographic Questionnaire, Organizational Culture Scale, Organizational Justice Perception Scale, and a scale containing questions concerning ethical conduct were given to participants between February 2, 2016 and April 2, 2016. An effort was 
made to survey nurses who worked the day shift. Due to the policy of the private hospital, the Coordinator for Nursing Services was informed about the surveys, then applied the scales, and returned them on the agreed deadline.

\subsection{Data Analysis}

Data was analysed using SPSS 15.0, whereby frequency, percentage, average and standard deviation were used for demographic information. The sub-dimensions of the values of frequency-percentage, arithmetical average, and standard deviation of the questions in the Organizational Justice Perception Scale and the Ethical Conduct Scale were subjected to examination. The results were evaluated with a confidence interval of $95 \%$ and a significance level of $P<0.05$. The relationship between the sub-dimensions of the perceptions of organizational culture and justice and that between the sub-dimensions of perception of organizational culture and ethical behavior was analyzed with the Pearson correlation method. Regression analysis was applied to determine the organizational culture and its effects on organizational justice and ethical behavior.

\section{Results}

A total of 153 nurses participated in the study of whom $78.4 \%$ were women, $56.2 \%$ were working in public hospitals, $46.4 \%$ were working in surgical units, $47.7 \%$ were undergraduates, $90.2 \%$ were nurses, and $72.6 \%$ found to be worked as a shift. The average age of the nurses participating in the study was $32.26 \pm 9.09$ years, and the average number of years working in the nursing profession was $11.77 \pm 9.25$ (Table 1 ).

The $t$ test was used to compare the nurses' perceptions of justice in the institutions where they served. Table 2 shows the statistical difference between the institution in which they work and their perception of informational justice $(P<0.05)$. Accordingly, the perception of informational justice of nurses serving in the private hospital $(3.59 \pm 1.04)$ was found to be higher than that of the nurses working in the public hospital.

The $t$ test was used to compare the sub-dimensions of nurses' perceptions of ethical behavior in the institutions in which they served. Table 3 shows the statistical difference between the institution in which they worked and their sub-dimensions of perceptions of ethical behavior $(P<0.05)$. Accordingly, the sub-dimensions of perceptions regarding ethical behavior of the nurses serving in the private hospital were found to be higher than those of nurses working in the public hospital.

The $t$ test was used to compare perceptions of organizational culture of the nurses towards the institutions in which they served. Table 4 shows the statistical difference between the institution in which they worked and their perceptions on organizational culture $(P<0.05)$. Accordingly, the sub-dimensions of organizational culture perceptions of nurses serving in the private hospital were found to be higher than those of nurses working in the public hospital.

Pursuant to the results shown in Table 5, a statistically
Table 1. Findings Related to Demographic Variables

\begin{tabular}{|c|c|c|c|}
\hline $\begin{array}{l}\text { Demographic } \\
\text { Information }\end{array}$ & Categories & No. & $\%$ \\
\hline \multirow{3}{*}{ Age } & $20-29$ & 71 & 46.4 \\
\hline & $30-39$ & 43 & 28.1 \\
\hline & $40-49$ & 39 & 25.4 \\
\hline \multirow{2}{*}{ Gender } & Female & 120 & 78.4 \\
\hline & Male & 33 & 21.6 \\
\hline \multirow{2}{*}{ Hospital } & Public & 86 & 56.2 \\
\hline & Private & 67 & 43.7 \\
\hline \multirow{3}{*}{ Worked clinic } & Surgical-internal clinics & 71 & 46.4 \\
\hline & Specialized clinics & 58 & 37.9 \\
\hline & Other $^{a}$ & 24 & 15.6 \\
\hline \multirow{3}{*}{ Alma mater } & Vocational school of health & 43 & 28.1 \\
\hline & Associate degree & 37 & 24.2 \\
\hline & Undergraduate & 73 & 47.7 \\
\hline \multirow{3}{*}{$\begin{array}{l}\text { Years of } \\
\text { professional } \\
\text { experience }\end{array}$} & $1-10$ & 82 & 59.6 \\
\hline & $11-20$ & 43 & 28.1 \\
\hline & $21+$ & 28 & 18.3 \\
\hline \multirow{2}{*}{ Position } & Nurse & 138 & 90.2 \\
\hline & Head nurse & 15 & 9.8 \\
\hline \multirow{2}{*}{ Manner of work } & Day shift & 42 & 27.4 \\
\hline & Shift & 111 & 72.6 \\
\hline
\end{tabular}

apoliclinic, bone marrow transplantation, VIP care, home care services.

significant and positive relationship was found between organizational justice and organizational culture perception $(P<0.001)$.

Regression analysis was applied to determine the relationship between the nurses' perceptions of organizational culture and organizational justice. The results indicated that organizational culture had a significant effect on organizational justice $(P=0)$.

Simple regression analysis was conducted to determine the impact of nurses' perceptions of organizational culture on organizational justice. It was determined that nurses' perceptions of organizational culture had an effect on organizational justice at a rate of $35 \%(\mathrm{R}=0.595 ; \mathrm{F}=$ 82.668; $P<0.001)$.

Pursuant to the results shown in Table 6, a statistically significant and positive relationship was found between nurses' perceptions of organizational justice and ethical behavior $(P<0.001)$.

Regression analysis was applied to determine the relationship between the nurses' perception of organizational culture and ethical conduct. The results indicated that organizational culture had a significant effect on ethical behavior $(P=0)$.

Simple regression analysis was conducted to determine the influence of nurses' perceptions of organizational culture on ethical behavior. It was determined that the nurses' perceptions of organizational culture had an effect on ethical behavior at a rate of $30 \%(\mathrm{R}=0.548 ; \mathrm{F}=64.955$; $P<0.001$ ).

According to the results, there was a significant relationship between the perceptions of organizational culture, ethical behavior and justice. Hierarchical regression 
Table 2. Difference Between the Institution of Nurses and the Sub-dimensions of the Perception of Justice

\begin{tabular}{lccccc}
\hline & $\begin{array}{c}\text { Operational Justice } \\
\text { Mean } \pm \text { SD }\end{array}$ & $\begin{array}{c}\text { Distributive Justice } \\
\text { Mean } \pm \text { SD }\end{array}$ & $\begin{array}{c}\text { Interpersonal Justice } \\
\text { Mean } \pm \text { SD }\end{array}$ & $\begin{array}{c}\text { Informational Justice } \\
\text { Mean } \pm \text { SD }\end{array}$ & $\begin{array}{c}\text { Overall Justice } \\
\text { Mean } \pm \text { SD }\end{array}$ \\
\hline Public $(\mathrm{n}=86)$ & $2.32 \pm 1.40$ & $2.30 \pm 1.52$ & $3.24 \pm 1.19$ & $3.11 \pm 1.30$ & $2.70 \pm 1.12$ \\
Private $(\mathrm{n}=67)$ & $2.59 \pm 1.32$ & $2.80 \pm 1.65$ & $3.41 \pm 0.93$ & $3.59 \pm 1.04$ & $3.04 \pm 1.02$ \\
& $t=-1.178$ & $t=-1.946$ & $t=-0.964$ & $t=-2.436$ & $t=-1.958$ \\
& $P=0.241$ & $P=0.053$ & $P=0.337$ & $P=0.016$ & $P=0.052$ \\
\hline
\end{tabular}

${ }^{a}$ Independent samples $t$ test.

Table 3. Difference Between the Institution of Nurses and the Sub-dimensions of Ethical Behavior

\begin{tabular}{|c|c|c|c|c|c|}
\hline Institution ${ }^{\mathrm{a}}$ & $\begin{array}{c}\text { Tolerance Dimension } \\
\text { Mean } \pm \text { SD }\end{array}$ & $\begin{array}{c}\text { Honesty Dimension } \\
\text { Mean } \pm \text { SD }\end{array}$ & $\begin{array}{c}\text { Justice Dimension } \\
\text { Mean } \pm \text { SD }\end{array}$ & $\begin{array}{c}\text { Responsibility Dimension } \\
\text { Mean } \pm \text { SD }\end{array}$ & $\begin{array}{c}\text { Overall Ethics } \\
\text { Mean } \pm \text { SD }\end{array}$ \\
\hline Public $(n=86)$ & $3.61 \pm 1.04$ & $3.97 \pm 0.87$ & $3.67 \pm 0.99$ & $3.79 \pm 0.87$ & $3.76 \pm 0.89$ \\
\hline Private $(n=67)$ & $3.95 \pm 0.92$ & $4.28 \pm 0.59$ & $4.07 \pm 0.85$ & $4.22 \pm 0.69$ & $4.14 \pm 0.69$ \\
\hline & $\begin{array}{l}t=-2.100 \\
P=0.037\end{array}$ & $\begin{array}{l}t=-2.469 \\
P=0.015\end{array}$ & $\begin{array}{l}t=-2.634 \\
P=0.009\end{array}$ & $\begin{array}{c}\mathrm{T}=-3.272 \\
P=.001\end{array}$ & $\begin{array}{l}t=-2.835 \\
P=0.005\end{array}$ \\
\hline
\end{tabular}

andependent samples $t$ test.

Table 4. Difference Between the Institution of Nurses and the Sub-dimensions of Organizational Culture

\begin{tabular}{lccccc}
\hline & $\begin{array}{c}\text { Power Culture } \\
\text { Institution }\end{array}$ & $\begin{array}{c}\text { Role Culture } \\
\text { Mean } \pm \text { SD }\end{array}$ & $\begin{array}{c}\text { Success Culture } \\
\text { Mean } \pm \text { SD }\end{array}$ & $\begin{array}{c}\text { Support Culture } \\
\text { Mean } \pm \text { S }\end{array}$ & $\begin{array}{c}\text { Overall Organizational Culture } \\
\text { Mean } \pm \text { SD }\end{array}$ \\
\hline Public $(\mathrm{n}=86)$ & $3.70 \pm 0.71$ & $3.74 \pm 0.64$ & $3,18 \pm 0.86$ & $3.36 \pm 0.86$ & $3.48 \pm 0.66$ \\
Private $(\mathrm{n}=67)$ & $4.03 \pm 0.70$ & $4.22 \pm 0.55$ & $3.55 \pm 0.82$ & $3.63 \pm 0.86$ & $3.83 \pm 0.61$ \\
& $t=-2.866$ & $t=-4.804$ & $t=-2660$ & $t=-1.947$ & $P .402$ \\
& $P=0005$ & $P=0$ & $P=0.009$ & $P=0.053$ & $P=0.001$ \\
\hline
\end{tabular}

andependent samples $t$ test.

analysis was conducted to determine the influence of ethical behavior and the perception of justice nurses' perceptions of organizational culture. The impact of ethical leadership and ethical behavior on organizational culture explained approximately $42 \%$ as a significant effect $(\beta=0.650 ; \mathrm{F}=$ 54.854; $P<0$ ). The results showed that ethical leadership behavior explained $32 \%$ of the organizational culture. Perceptions of organizational justice were found to explain $42 \%$ of organizational culture.

\section{Discussion}

The current study investigated the perceptions of nurses serving in hospitals regarding organizational culture, organizational justice, and ethical behavior and aimed to determine the effects of organizational culture on justice and ethical behavior.

Even though a considerable amount of literature has already been published on nurses, little is available on organizational culture, organizational justice, and ethical matters. Nurses serving at management levels must face justice and ethical problems, irrespective of whether they work in a private, public, or university hospital. In this context, it is highly probable that the organizational structures of hospitals have an effect on the behavior of employees in terms of justice and ethical matters. Thus, providing insights into the effects of the organizational culture on the ethical behavior and perception of justice of nurses, the results of the current study contribute to the existing literature on nurses and provides support for further research.

Examining the sub-dimensions of perception of organizational justice, it was seen that nurses are of the opinion that they are mostly subjected to inequitable behavior in the dimension of operational justice $(2.44 \pm 1.37)$. The highest average was found in the perception of informational justice $(3.32 \pm 1.22)$. In particular, the question "Are these processes applied in a prejudice-free environment?" had the lowest average $(2.29 \pm 1.62)$. This result led to the assumption that nurses' perceptions, in general, are that decision-making processes regarding pay, promotions, etc. are not fair. In his study carried out in 2016 with 231 employees working in the textile sector, Yalap found that operational justice had the lowest average $(2.81 \pm 0.94)$. In the same study, the question with the lowest average was "Are all employees of this institution consulted before making a decision regarding work?" $(2.63 \pm 1.19) .{ }^{12}$ The question with the highest average in the study was "Is the language of information understandable to everybody?" (3.59 \pm 1.30$)$, which indicates that managers use an understandable language when informing nurses about processes. In his study conducted with 327 nurses in 2014, Gür also found, based on the evaluation of the sub-items of perception of organizational justice, that this question had the highest average $(3.93 \pm 0.99) .{ }^{13}$

In examining the sub-dimensions of perceptions of organizational culture, it was observed that the sub-dimension of role factor had the highest average 
Table 5. Correlation Between Nurses' Perceptions of Organizational Culture and Justice

\begin{tabular}{|c|c|c|c|c|c|c|c|c|c|c|}
\hline & \multicolumn{2}{|c|}{ Operational Justice } & \multicolumn{2}{|c|}{ Distributive Justice } & \multicolumn{2}{|c|}{ Interpersonal Justice } & \multicolumn{2}{|c|}{ Informational Justice } & \multicolumn{2}{|c|}{ Overall Justice } \\
\hline & $r$ & $P$ & $r$ & $\boldsymbol{P}$ & $r$ & $\boldsymbol{P}$ & $r$ & $\boldsymbol{P}$ & $r$ & $P$ \\
\hline Power culture & 0.340 & 0 & 0.334 & 0 & 0.322 & 0 & 0.403 & 0 & 0.423 & 0 \\
\hline Role culture & 0.262 & 0.001 & 0.249 & 0.002 & 0.329 & 0 & 0.360 & 0 & 0.354 & 0 \\
\hline Success culture & 0.602 & 0 & 0.423 & 0 & 0.438 & 0 & 0.449 & 0 & 0.601 & 0 \\
\hline Support culture & 0.540 & 0 & 0.398 & 0 & 0.486 & 0 & 0.510 & 0 & 0.592 & 0 \\
\hline $\begin{array}{l}\text { Overall organizational } \\
\text { culture }\end{array}$ & 0.537 & 0.000 & 0.417 & 0 & 0.475 & 0 & 0.512 & 0 & 0.595 & 0 \\
\hline
\end{tabular}

${ }^{a} P<0.001$.

Table 6. Correlation Between Nurses' Perceptions of Organizational Culture and Ethical Behavior

\begin{tabular}{|c|c|c|c|c|c|c|c|c|c|c|}
\hline & \multicolumn{2}{|c|}{ Tolerance Dimension } & \multicolumn{2}{|c|}{ Honesty Dimension } & \multicolumn{2}{|c|}{ Justice Dimension } & \multicolumn{2}{|c|}{$\begin{array}{l}\text { Responsibility } \\
\text { Dimension }\end{array}$} & \multicolumn{2}{|c|}{ Overall } \\
\hline & Ethics & $P$ & $r$ & $P$ & $r$ & $P$ & $r$ & $P$ & $r$ & $P$ \\
\hline Power culture & 0.314 & 0 & 0.400 & 0 & 0.408 & 0 & 0.438 & 0 & 0.418 & 0 \\
\hline Role culture & 0.359 & 0 & 0.385 & 0 & 0.421 & 0 & 0.486 & 0 & 0.445 & 0 \\
\hline Success culture & 0.459 & 0 & 0.421 & 0 & 0.484 & 0 & 0.448 & 0 & 0.484 & 0 \\
\hline Support culture & 0.488 & 0 & 0.467 & 0 & 0.484 & 0 & 0.482 & 0 & 0.514 & 0 \\
\hline $\begin{array}{l}\text { Overall organizational } \\
\text { culture }\end{array}$ & 0.486 & 0 & 0.488 & 0 & 0.529 & 0 & 0.540 & 0 & 0.548 & 0 \\
\hline
\end{tabular}

a $P<0.001$.

$(3.95 \pm 0.64)$. The question "Emphasis is attached to the execution of work in due time and by the rules" had the highest average $(4.24 \pm 0.87)$, a result which led to the assumption that nurses are aware of their duties and responsibilities and act in accordance with them. The result generated on the basis of the question "Success is taken as a basis for rewarding," on the other hand, had the lowest average $(2.87 \pm 1.35)$. Based on this result, it can be said that the factor of success is not taken into account by the institution in rewarding the employees. A study carried out by İpek in 1999 with 2002 administrators, teachers, and students found that, while the factor of power had the highest average and support had the lowest in state gymnasiums, the factor of success turned out to be the one with the highest average and the factor of role had the lowest average in public gymnasiums. ${ }^{9}$

An examination of the sub-dimensions of perception of ethical behavior showed that the sub-dimension of the honesty factor had the highest average $(4.11 \pm 0.77)$. The factor of tolerance was found to have the lowest average (3.76 \pm 0.10$)$. In particular, the items "The rules of discipline and punishment fairly cover the disobedient behavior" (3.65 \pm 1.13$)$ and "Judgments based on objective considerations" $(3.87 \pm 1.11)$ were found to have the lowest average. The item with the highest average was "Involved in no corruption" $(4.46 \pm 0.91)$. The study results showed that while managing nurses adopt minimal ethical behavior in the dimension of tolerance, the maximum ethical behavior is observed in the dimension of honesty.

Attitudes and behaviors of managers are crucial to establishing a peaceful and fair work environment. Unfairness refers to the belief by an individual that he/she is treated unfairly. This perception is related to whether individuals feel equal when they compare themselves with others. ${ }^{4}$ The current study found a statistically significant relationship at a medium level (positive) between the overall perception of nurses regarding organizational justice and the overall perception of nurses regarding culture $(r=0.595 ; P<0.01)$. This finding leads to the conclusion that nurses do develop a positive perception of organizational justice with higher sub-dimensions when the institution for which they work has a sound infrastructure in the dimensions of power, role, success, and support. The findings also indicated that institutions which have fair pay scales, apply a pay, promotion, and reward system in compliance with performance, include employees in decision-making processes concerning personnel would be more powerful in the dimensions of organizational culture (power, role, success, support). Accordingly, a positive perception by nurses of justice is also a factor that would motivate employees, increase loyalty and confidence in the institution, enhance an institution's values, have a positive effect on the communication and co-existence of employees, make possible the development of new standards in work methods and processes, and provide better, qualified services. In other words, no unfair conduct would be observed in dynamic institutions where the organizational structure supports success and roles are distributed in a fair and equitable environment.

The current study found a statistically significant relationship at a medium level (positive) between the perceptions of nurses regarding overall organizational culture and overall ethical behavior $(r=0.548 ; P<0.01)$. This finding supports the assumption that the cultural structure of a hospital is powerful in the dimensions of power, role, success, and support when the managing personnel adopt a tolerant, fair, and responsible conduct towards employees. It is not only the conduct of employees 
that affect the structure of an institution; the conduct of managers also has a great effect on an institution's overall capacity, shaping its direction and future.

\section{Conclusion}

From the study results, it can be concluded that an institution where managing personnel assume responsibilities in line with professional and ethical principles, adopting a warm, honest, tolerant, and equitable conduct towards employees would provide a positive cultural structure.

\section{Limitations of the Study}

The current study was carried out on a small sample and only investigated those nurses serving at the managing level in one public and one private hospital in Ankara. The researcher received no permission to conduct surveys in hospitals under the Ministry of Healthcare. As the notions of justice, ethics, and culture were evaluated on the basis of the perceptions of nurses, the results fail to reflect the real situation. Also, the participants had to respond to a comparatively high number of questions. On the grounds of all these limitations, the current study provides no results which can be extrapolated outside the sampling universe.

\section{Authors' Contributions}

Study Design: ZÖ and DE; Data Collection: ZÖ; Data Analysis: ZÖ; Manuscript writing: DE and ZÖ.

\section{Conflict of Interest Disclosures}

No conflicts of interest are declared.

\section{Ethical Approval}

The current study obtained ethical permission from the Gazi University Ethical Approval Board (Number: 77082166-604.01.02).

\section{References}

1. Erdoğan İ. Organizational Behaviours. Istanbul: Miad Publishing; 2007:223. (Turkish).

2. Bakan İ, Büyükbeşe T, Bedestenci HÇ. Organizational CultureTheoretical and Empirical Approach. 1st ed. Istanbul: Alfa Academy Publishing; 2004. (Turkish).

3. Ataman G. Business Management: Basic Concepts and New Approaches. 2nd ed. Istanbul: Türkmen Publishing; 2002.

\section{Research Highlights}

\section{What Is Already Known?}

The ethical and just behavior exhibited by managers influences the organizational culture that is perceived by employees.

\section{What This Study Adds?}

Nurses in their work culture that have a significant impact on perceptions of justice and ethical behaviours, exposed in the case of increasing of non-ethic and non-justice behaviours it was the nurses perceive more strength and role culture.

4. Greenberg J. A taxonomy of organizational justice theories. Acad Manage Rev. 1987;12(1):9-22. doi:10.5465/ AMR. 1987.4306437.

5. Yılmaz G. The Effect of Organizational Justice Perception Regarding Human Resource Practices on Employess Attitudes and Behaviors [dissertation]. Istanbul: Istanbul University Social Sciences Institute; 2004.

6. Kara Y. The Effect of Organizational Culture in Schools on Ethical Manners of School Executives [thesis]. Istanbul: Istanbul University Social Sciences Institute; 2006.

7. Aydın IP. Managerial, Professional and Organizational Ethics. 3rd ed. Ankara: Pegem Publishing; 2002.

8. Marquis $\mathrm{BL}$, Huston CJ. Leadership Roles and Management Functions in Nursing. 4th ed. Philadelphia: Lippincott Williams \& Wilkins: 2003:68.

9. İpek C. Organizational Culture Teacher-Student Relationship in Public and Private Secondary Schools [dissertation]. Ankara: Ankara University Social Sciences Institute; 1999.

10. Colquitt JA, Conlon DE, Wesson MJ, Porter CO, Ng KY. Justice at the millennium: a meta-analytic review of 25 years of organizational justice research. J Appl Psychol. 2001;86(3):425445.

11. Özmen ÖNT, Arbak Y, Özer PS. An inquiry about the effect of justice value on justice perception. Ege Akademik Bakış/Ege Academic Review. 2007;7(1):17-33.

12. Yalap O. The Impact Of Perceptions Of Organizational Justice For Employess On Organizational Deviance Behaviours: A Research In The Textile Industry [thesis]. Tokat: Gaziosmanpaşa University Social Sciences Institute; 2016:70.

13. Gür E. Organizatıonal Justice Perception and Burnout Situations of Nurses Working in Public, Private and University Hospitals [thesis]. Ankara: Gazi University Graduate School of Health Sciences; 2004 